\title{
Growth retardation in patients with juvenile idiopathic arthritis and growth hormone therapy I Nikishina* and A Shapovalenko
}

Address: Institute of Rheumatology of RAMS, Moscow, Russian Federation

* Corresponding author

from $15^{\text {th }}$ Paediatric Rheumatology European Society (PreS) Congress

London, UK. 14-17 September 2008

Published: 15 September 2008

Pediatric Rheumatology 2008, 6(Suppl I):P50 doi:I0.I I86/I546-0096-6-SI-P50

This abstract is available from: http://www.ped-rheum.com/content/6/SI/P50

(C) 2008 Nikishina and Shapovalenko; licensee BioMed Central Ltd.

\section{Objective}

To identify patient characteristics, that predict the growth retardation and to assess the risk/benefits proportion of growth hormone $(\mathrm{GH})$ treatment in JIA patients.

\section{Methods}

Study cohort was presented by 170 JIA patients (47 boys, 123 girls, mean age 12.1, disease duration $5.1 \mathrm{yrs}$ ). Annual growth parameters were studied in relation with premorbid and disease related factors. 30 prepubertal patients, having the most significant delay of growing were randomized in 2 groups. 15 patients were received recombinant GH 0,05-0,07 mg/kg within 4-18 months; other 15 patients were as control.

\section{Results}

Growth retardation was observed in 40\% (height SDS $\leq$ 2 ). It was associated with systemic variant (43.3\% versus $13.4 \%$ in patients with normal height), disease duration $(7.9 \pm 3.4$ vs $6.3 \pm 3.1$ yrs $)$, ESR levels $(47.7 \pm 14.8$ vs 29.2 \pm 14.8 ), number of active joints, glucocorticosteroid treatment independent of doses. Short stature in family cases $(19,4 \%$ vs $2,3 \%)$ and father's height SDS $(-0,49 \pm 0,1$ vs $0,17 \pm 0,4)$ obtained more often in patients with growth retardation. There are no abnormality of $\mathrm{GH}$ secretion in JIA patients. A significant response to GH treatment compared with control group was seen in all children. The median height velocity was $3.1 \mathrm{~cm}$ per 3 months (4-12.5 $\mathrm{cm} / 1$ year). We observed the disease increasing activity in 8/15 patients under GH therapy. Other complications from GH-therapy were not marked.

\section{Conclusion}

We conclude that disease activity and genetic factors are the most important reasons of growth retardation in JIA patients. Recombinant GH may be of benefit in severe growth retardation therapy, but can promote disease activity. 